\section{Carotid blowout syndrome: An oncological emergency less discussed}

DOI: $10.4103 /$ sajc.sajc_211_16

Dear Editor,

Carotid blowout syndrome (CBS) is a rare but life-threatening complication of head and neck cancer. Most commonly, patients have a history of squamous cell carcinoma and have undergone prior radical neck surgery and radiation therapy. ${ }^{[1]}$ Bleeding from the oral cavity and from an exposed neck wound are the common symptoms. Advances in interventional radiology have made management of these conditions possible which was difficult earlier. We hereby present a case of acute CBS in a case of recurrent carcinoma of hypopharynx, who was actively managed by parent vascular occlusion.

\section{Case Report}

A 60 -year-old male presented to casualty with bleeding from the oral cavity. Examination showed large clots in the oral cavity. The patient was in shock. Hemogram revealed hemoglobin was found to be $6.1 \mathrm{~g} / \mathrm{dl}$. Coagulation profile was normal. Fluid replacement and blood transfusion were given, and the patient was stabilized.

The patient was a known case of carcinoma of hypopharynx and had completed induction chemotherapy followed by concurrent chemoradiation a year back, now with recurrence. Endoscopy showed a large eccentric friable mass lesion in the hypopharynx associated with bleeding. CBS was suspected, and angiography was ordered. Magnetic resonance angiography showed the lesion completely encasing the proximal $2 \mathrm{~cm}$ of external carotid artery with minimal luminal narrowing. No obvious dissection or pseudoaneurysm was seen.

Interventional radiologist was consulted. Transfemoral supra-aortic digital subtraction angiogram showed active contrast extravasation from anterior wall of left external carotid artery just distal to its origin [Figure 1a]. The contrast is seen tracking into pharynx, esophagus, and oral cavity.

Embolization using 35-3-3 coil was done, following which no active extravasation of dye was noted. A tiny stump of the left external carotid artery was seen which was consistent with successful embolization [Figure 1b]. Postembolization patient was stable.

\section{Discussion}

CBS is known to occur in $4.3 \%$ of head and neck malignancies. ${ }^{[2]}$ Involvement of the carotid artery by malignant processes of the head and neck with compromise of vessel integrity and rupture is called "CBS." It is associated with a mortality and morbidity of $40 \%$ and $60 \%$, respectively. ${ }^{[3]}$

CBS is often a complication of squamous cell carcinoma of the head and neck, particularly the cases treated with radiotherapy and/or neck dissection. Radiation has been implicated to obliterate the vasa vasorum, causing fibrosis of the adventitia, weakening of the arterial wall, and thus leading to rupture. ${ }^{[4]}$ In the present case, both prior radiotherapy and recurrence were risk factors.

CBS is classified as threatened, impending, or acute. CBS has been categorized by Chaloupka et al. as "threatened," where

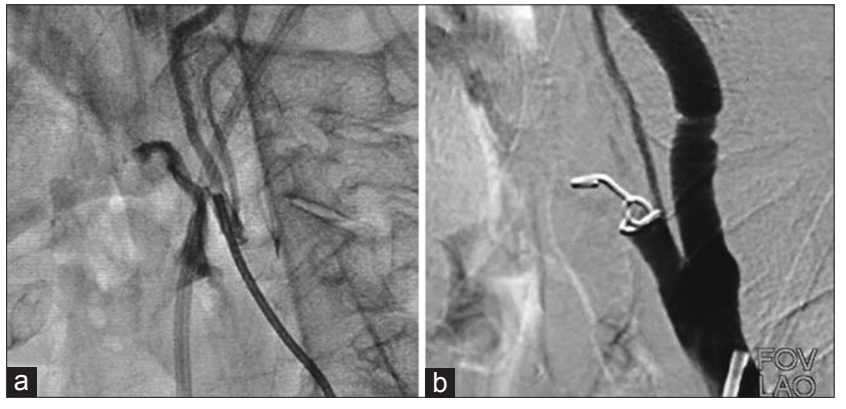

Figure 1: (a) Preembolization: Left external carotid artery showed active contrast extravasation just distal to its origin. (b) Postembolization: a tiny stump of left external carotid artery seen consistent with successful embolization

the carotid artery is exposed to the oral cavity or external environment through skin breakdown or by direct tumor invasion; "impending," in which sentinel bleeds have occurred but have been controlled by conservative management; or "acute," where there is active bleeding. ${ }^{[5]}$

The gold standard for diagnosing CBS is digital subtraction angiography. In patients presenting with threatened and impending CBS, a CT angiogram of the head and neck is reasonable to evaluate the carotid circulation up to the circle of Willis. ${ }^{[6]}$

Following diagnosis, immediate treatment is crucial and focuses on aggressive critical care with securing the airway and management of hemorrhagic shock. ${ }^{[7]}$

Traditional surgical ligation had been the only choice in the past with a displeasingly high rate of neurological morbidity and mortality due to altered anatomy as a result of prior surgery or radiation. Hence, CBSs main treatment has shifted to endovascular techniques: either embolization or stenting of parent artery. ${ }^{[4]}$ Lesley et al. describe a $15 \%-20 \%$ rate of acute or delayed cerebral ischemia following occlusion, which can be predicted by a balloon occlusion test. This test may however be bypassed in acute cases. ${ }^{[8]}$

Endovascular stents are considered in patients who are at high risk for cerebral ischemia such as those who have an incomplete circle of Willis or occluded contralateral common carotid artery. With increased availability and smaller delivery systems, covered stents are an attractive alternative for CBS. ${ }^{[9]}$ However, long-term results have been less encouraging, with high rates of technical complications including cerebral thromboembolism by the inadequate antiplatelet medication, septic thrombosis of the stent graft, and delayed stenosis/ occlusion of the carotid artery by the strong radial force of the stent graft. ${ }^{[10,11]}$

Patients with acute CBS were associated with a higher rebleeding rate than those with impending and threatened CBS. Rebleeding occurs due to reconstitution of collateral vessels or recanalization of the thrombosed carotid artery. Cross occlusion is preferred in such cases to enhance durable hemostasis. For all patients, clinical severity is the significant factor affecting the hemostatic outcome of endovascular management. ${ }^{[12]}$

A sequential approach of treating impending CBS with induction chemotherapy, embolization, and radiation therapy has also been successfully employed. ${ }^{[13]}$ 
The head neck cancer team should be alert for predictors of CBS such as pseudoaneurysm formation and vessel wall damage. ${ }^{[1]}$

\section{Conclusion}

With an increasing population of treated head and neck cancer cases, the oncologist must be alert to any recent history of oral bleeding or hemorrhage from an exposed neck wound. Once CBS is suspected by the emergency physicians, interventional radiologist must be contacted immediately for expeditious diagnosis and intervention. Parent vascular occlusion is the preferred method of management and covered stents is an option in patients who are not candidates for parent vascular occlusion. Early recognition of the predictors of CBS by a multidisciplinary team is crucial.

\section{Financial support and sponsorship}

Nil.

\section{Conflicts of interest}

There are no conflicts of interest.

Karthik K. Prasad, Nagesh T. Sirsath', Kiran V. Naiknaware ${ }^{2}$, K. Sandhya Rani ${ }^{3}$, Manish S Bhatia Departments of Surgical Oncology, 'Medical Oncology, ${ }^{2}$ Interventional Radiology and ${ }^{3}$ Radiation Oncology, M N Budhrani Cancer Institute, Pune, Maharashtra, India Correspondence to: Dr. Karthik K. Prasad, E-mail: drkrishkarthik@gmail.com

\section{References}

1. Powitzky R, Vasan N, Krempl G, Medina J. Carotid blowout in patients with head and neck cancer. Ann Otol Rhinol Laryngol 2010;119:476-84.

2. Maran AG, Amin M, Wilson JA. Radical neck dissection: A 19-year experience. J Laryngol Otol 1989; 103:760-4.

3. Citardi MJ, Chaloupka JC, Son YH, Ariyan S, Sasaki CT. Management of carotid artery rupture by monitored endovascular therapeutic occlusion (1988-1994). Laryngoscope 1995;105:1086-92.
4. Cohen J, Rad I. Contemporary management of carotid blowout. Curr Opin Otolaryngol Head Neck Surg 2004; 12:110-5.

5. Chaloupka JC, Putman CM, Citardi MJ, Ross DA, Sasaki CT. Endovascular therapy for the carotid blowout syndrome in head and neck surgical patients: Diagnostic and managerial considerations. AJNR Am J Neuroradiol 1996; 17:843-52.

6. Kozin E, Kapo J, Straton J, Rosielle DA. Carotid blowout management \#251. J Palliat Med 2012;15:360-1.

7. Borno HK, Menendez RJ, Chaloupka JC, Dalley MT, Farcy DA. Carotid artery blowout producing massive hematemesis in the emergency department. J Acute Dis 2016;5:165-7.

8. Lesley WS, Chaloupka JC, Weigele JB, Mangla S, Dogar MA. Preliminary experience with endovascular reconstruction for the management of carotid blowout syndrome. AJNR Am J Neuroradiol 2003;24:975-81.

9. Haas RA, Ahn SH. Interventional management of head and neck emergencies: Carotid blowout. Semin Intervent Radiol 2013;30:245-8.

10. Chang FC, Luo CB, Lirng JF, Lin CJ, Lee HJ, Wu CC, et al. Endovascular Management of post-irradiated carotid blowout syndrome. PLoS One 2015; 10:e0139821.

11. Chang FC, Lirng JF, Luo CB, Guo WY, Teng MM, Tai SK, et al. Carotid blowout syndrome in patients with head-and-neck cancers: Reconstructive management by self-expandable stent-grafts. AJNR Am J Neuroradiol 2007;28: 181-8.

12. Chang FC, Lirng JF, Luo CB, Wang SJ, Wu HM, Guo WY, et al. Patients with head and neck cancers and associated postirradiated carotid blowout syndrome: Endovascular therapeutic methods and outcomes. JVasc Surg 2008;47:936-45.

13. Peguero J, Khanfar A, Mannem S, Willis M, Markowtiz A. Impending carotid blowout syndrome. J Clin Oncol 2015;33:e97-8.

This is an open access article distributed under the terms of the Creative Commons Attribution-NonCommercial-ShareAlike 3.0 License, which allows others to remix tweak, and build upon the work non-commercially, as long as the author is credited and the new creations are licensed under the identical terms.

How to cite this article: Prasad KK, Sirsath NT, Naiknaware KV, Rani KS, Bhatia MS. Carotid blowout syndrome: An oncological emergency less discussed. South Asian J Cancer 2017;6:85-6.

(c) 2017 The South Asian Journal of Cancer | Published by Wolters Kluwer - Medknow 